BNL-112592-2016-JA

\title{
Properties of Poly- and Oligo-Pentacenes Synthesized from Modular Building Blocks
}

Elango Kumarasamy, Samuel N. Sanders, Andrew B. Pun, Saeed Ahmadi Vaselabadi, Jonathan Z. Low, Matthew Y. Sfeir, Michael L. Steigerwald, Gila Stein, and Luis M. Campos

Submitted to Macromolecules

February 2016

\author{
Center for Functional Nanomaterials
}

Brookhaven National Laboratory

\section{U.S. Department of Energy Office of Science, DOE Basic Energy Science}

Notice: This manuscript has been authored by employees of Brookhaven Science Associates, LLC under Contract No. DE- SC0012704 with the U.S. Department of Energy. The publisher by accepting the manuscript for publication acknowledges that the United States Government retains a non-exclusive, paid-up, irrevocable, world-wide license to publish or reproduce the published form of this manuscript, or allow others to do so, for United States Government purposes. 


\section{DISCLAIMER}

This report was prepared as an account of work sponsored by an agency of the United States Government. Neither the United States Government nor any agency thereof, nor any of their employees, nor any of their contractors, subcontractors, or their employees, makes any warranty, express or implied, or assumes any legal liability or responsibility for the accuracy, completeness, or any third party's use or the results of such use of any information, apparatus, product, or process disclosed, or represents that its use would not infringe privately owned rights. Reference herein to any specific commercial product, process, or service by trade name, trademark, manufacturer, or otherwise, does not necessarily constitute or imply its endorsement, recommendation, or favoring by the United States Government or any agency thereof or its contractors or subcontractors. The views and opinions of authors expressed herein do not necessarily state or reflect those of the United States Government or any agency thereof. 


\title{
Properties of Poly- and Oligo-Pentacenes Synthesized from Modular Building Blocks
}

\author{
Elango Kumarasamy, ${ }^{1, \$}$ Samuel N. Sanders, ${ }^{1,}$ Andrew B. Pun, ${ }^{1}$ Saeed Ahmadi Vaselabadi, ${ }^{2}$ Jona- \\ than Z. Low, ${ }^{1}$ Matthew Y. Sfeir, ${ }^{3}$ Michael L. Steigerwald, ${ }^{1}$ Gila Stein, ${ }^{2}$ and Luis M. Campos ${ }^{1, *}$ \\ 1) Department of Chemistry, Columbia University, New York, New York 10027, United States. \\ 2) Department of Chemical and Biomolecular Engineering, University of Houston, Houston, Texas 77204, United \\ States
}

3) Center for Functional Nanomaterials, Brookhaven National Laboratory, Upton, New York 11973, United States

KEYWORDS: Pentacene oligomers; Polypentacene; Regiopure pentacenes; Acenes;

\begin{abstract}
We describe a facile route to well-defined, solution-processable pentacene oligomers (2 to 7 ) and homopolymer using Suzuki-Miyaura cross coupling reactions. Because this synthetic strategy leads to regioisomers, regiopure syn and anti trimers were also synthesized, revealing minimal changes in solution properties but significant changes in the solid state resulting from differing levels of crystallinity. The materials were characterized by steady state absorption spectroscopy and cyclic voltammetry to study their electronic structure. The steady state absorption spectra exhibit a new high-energy transition in the oligomers, which intensifies as a function of oligomer length, thus increasing the range of absorption to include the entire visible spectrum. Density functional theory calculations indicate that the new peak results directly from the oligomerization. Solid state UV-vis suggests that while the monomer is amorphous, bricklayer packing in the higher oligomers significantly alters the solid-state absorption relative to solution. This effect of oligomerization on packing was corroborated by GIWAXS analysis, which revealed crystalline domains in the oligomers. These domains, which are most evident in anti-trimer, become more pronounced upon thermal annealing. Photodegradation studies revealed considerable stability enhancement of oligomers towards oxygen and cycloaddition reactions relative to monomer. The synthesis and characterization of the first higher oligomers and homopolymer of pentacene should pave the way to applications in singlet fission, organic field effect transistors, and organic photovoltaics.
\end{abstract}

\section{INTRODUCTION}

Acenes are of great interest in the field of organic electronics due to their tunable optoelectronic properties, high charge carrier mobilities, and the observation of singlet exciton fission (SF) in crystals of tetracene and higher acenes. ${ }^{1}$ Pentacene is of particular interest, as it is a benchmark material for organic field effect transistors (OFETs) and organic photovoltaics (OPVs), as well as fundamental studies of various optoelectronic properties. ${ }^{2}$ However, pentacene has only limited stability and solubility in common organic solvents and is unstable in the presence of oxygen, ${ }^{3}$ making it difficult to process by high throughput techniques. ${ }^{1 \mathrm{c}, 4}$ To overcome these limitations, several functionalized pentacenes have been reported, which exhibit enhanced solubility, stability, and tunable electronic properties. ${ }^{2 \mathrm{~b}, 5}$ Despite these improvements, over the course of nearly 80 years of significant research in pentacene chemistry and physics, there has been only one report of short conjugated oligomers, a scarce number of conjugated pentacene-containing polymers, and a pentacene homopolymer remains unknown. ${ }^{6}$ In order to understand the effects of increasing the oligomerization length on the fundamental properties of oligomers and polymers of pentacenes, we developed building blocks to access oligomers (2-7) as well as polypentacene.

\section{Scheme 1.}

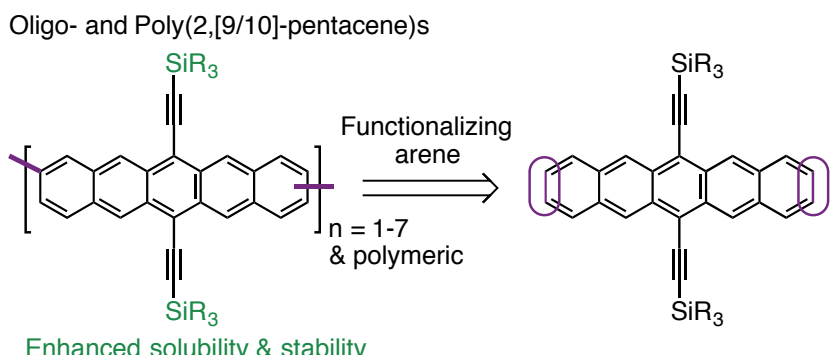

Obtaining well-defined oligomeric materials is particularly attractive because they reveal detailed structureproperty relationships, as in the case of thiophenes. ${ }^{7}$ To date, pentacene has only been incorporated in alternating 
copolymers or as a pendant group on a polymer chain, not as a homopolymer. ${ }^{6}$ Tykwinski and co-workers developed an attractive strategy where the pentacenes were not directly coupled, but included a diacetylene spacer in an alternating fashion linked at the 6 and 13 positions. ${ }^{6 \mathrm{~d}}$ Unfortunately, higher oligomers $(n>4)$ could not be synthesized employing this strategy due to limited solubility, which results from the decreasing ratio of the solubilizing trialkylsilane unit to pentacene, upon oligomerization. This decreasing ratio can also be detrimental to stability, as the bulky alkylsilyl groups protect against the primary degradation pathways of dimerization and photooxidation. $^{5 \mathrm{a}}$ An alternative strategy is needed to access higher oligomers of conjugated pentacene and polypentacene in order to study the optoelectronic properties. Our strategy, shown in Scheme 1, employs coupling at the $2,[9 / 10]$ positions, which allows us to retain the solubilizing/stabilizing functionalities at the 6 and 13 positions on every monomer unit in the oligomer. This strategy overcomes previous limitations, finally allowing for synthesis and characterization of well-defined conjugated oligomers of pentacenes $(n=1-7)$, in addition to a soluble homopolymer of pentacene by step-growth polymerization.

\section{RESULTS AND DISCUSSION}

Synthesis: The building blocks shown in Scheme 2 were designed to access well-defined pentacene oligomers and polypentacene, which are synthesized in multi-gram scales, and are soluble and stable. All materials stem from the primary pentacenes $\mathbf{1} \mathbf{A}$ and $\mathbf{1} \mathbf{A} \mathbf{2},{ }^{6 \mathrm{~b}}$ which are borylated to $\mathbf{1 B}$ and $\mathbf{1 B 2}$ under mild conditions (details in supporting information). Using these four primary building blocks, the secondary and tertiary building blocks are synthesized in good yields. Subsequent palladiumcatalyzed cross-couplings in the combinations shown in Scheme 2 yield the oligopentacenes of interest.

\section{Scheme 2.}
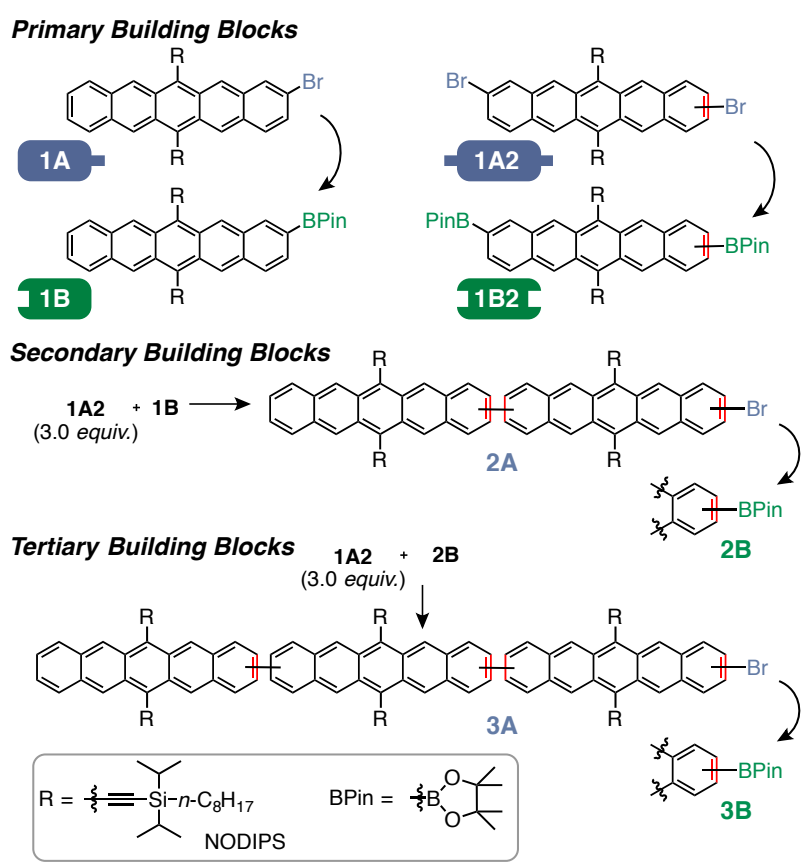

Oligopentacene Synthesis Approach

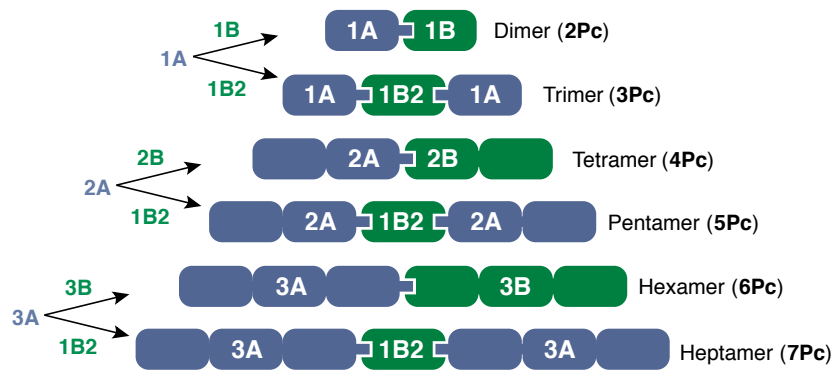

Our initial attempts to synthesize oligopentacenes contained triisopropylsilylethynyl groups (TIPS) as the solubilizing unit. Unfortunately, TIPS was not sufficiently solubilizing for pentacene oligomers with more than three repeat units. To overcome this problem, we turned to n-octyl-diisopropylsilylethynyl (NODIPS), which Anthony and co-workers had previously demonstrated as a better solubilizing group for pentacenes. ${ }^{8}$ The synthesis of the pentacene core has been well-established in the literature and is detailed in the supporting information. ${ }^{9}$ The oligopentacenes exhibit excellent solubility in solvents such as THF and chlorinated solvents (DCM and chloroform).

While this synthetic strategy is modular in nature and allows synthesis of higher oligomers, the products are regioisomeric mixtures because $\mathbf{1 A 2}$ is a mixture of $\mathbf{2}^{2} \mathbf{9}^{-}$ dibromopentacene (anti) and 2,10-dibromopentacene (syn) derivatives. ${ }^{10}$ We were interested in exploring the effect of this regioisomerism on the properties of the resultant oligomers. The two regioisomers of the trimer, syn-3Pc and anti-3Pc (Scheme 3), were synthesized using Bao and coworker's selective crystallization strategy for regiopure syn and anti-dibromopentacenequinone. ${ }^{11}$ We compare the properties of these regiopure trimers below. Beyond trimer, exhaustive exploration of possible regioisomers was precluded by the exponentially increasing number of regioisomers, as well as the many steps and 
difficulties in acquiring large quantities of regiopure dibromoquinone starting material.

\section{Scheme 3.}
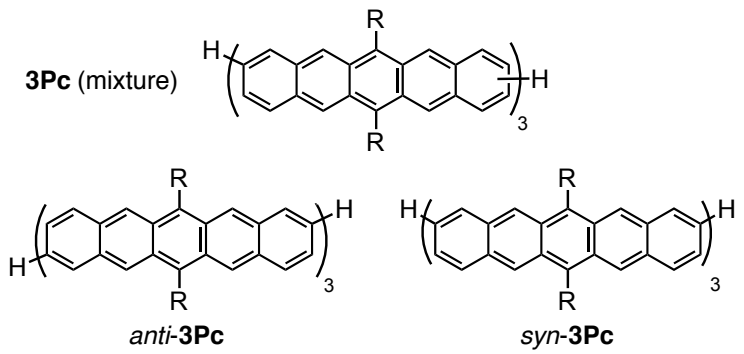

The oligomers up to ${ }_{3} \mathbf{P c}$ were readily characterized by NMR spectroscopy and high-resolution mass spectrometry. However, NMR spectroscopic characterization of oligomers $>\mathbf{4}$ Pc was hampered by peak broadening which was prevalent even at elevated temperature $\left({ }^{1} \mathrm{H}\right.$ NMR at $50{ }^{\circ} \mathrm{C}$ ). This peak broadening is the result of several factors such as the presence of regioisomers, similar location of aromatic protons on adjacent pentacenes and decreasing symmetry in higher oligomers. ${ }^{10}$ In order to definitively assign the identity of the oligomers ${ }_{4-7} \mathbf{P c},{ }^{1} \mathrm{H}$ NMR was corroborated by MALDI mass spectrometry.

Scheme 4 .

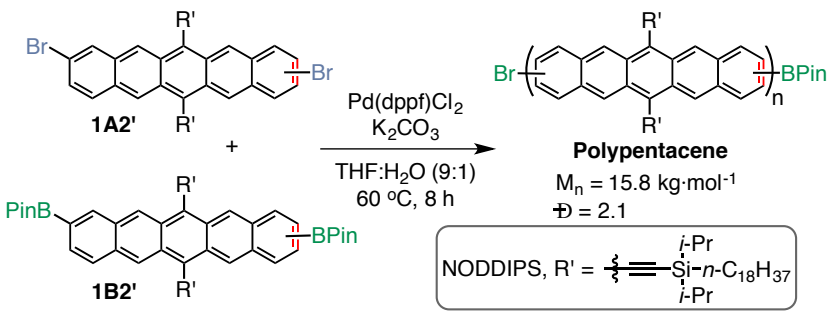

An effort to obtain polypentacene was carried out by stepgrowth polymerization of $\mathbf{1 A 2}$ and $\mathbf{1 B 2}$. The initial attempt on polymerization at $65{ }^{\circ} \mathrm{C}$ for 3 days resulted in an insoluble black solid. Reduction of the temperature or reaction time only resulted in oligomers of pentacenes as determined by mass spectrometry. This result indicated that the NODIPS chain is insufficient to produce soluble polypentacenes. 
A)

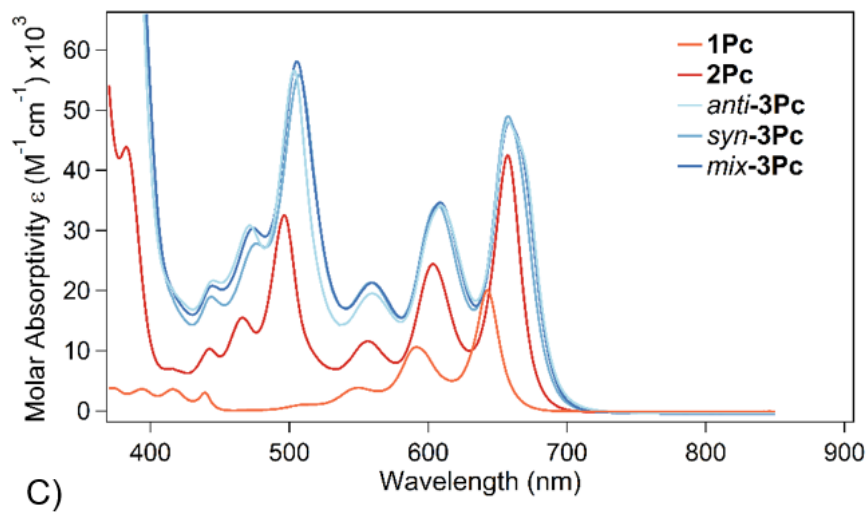

C)

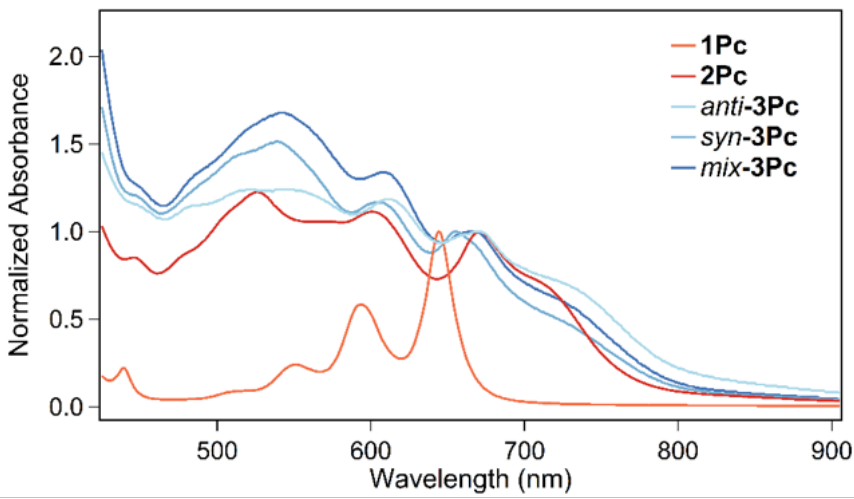

B)
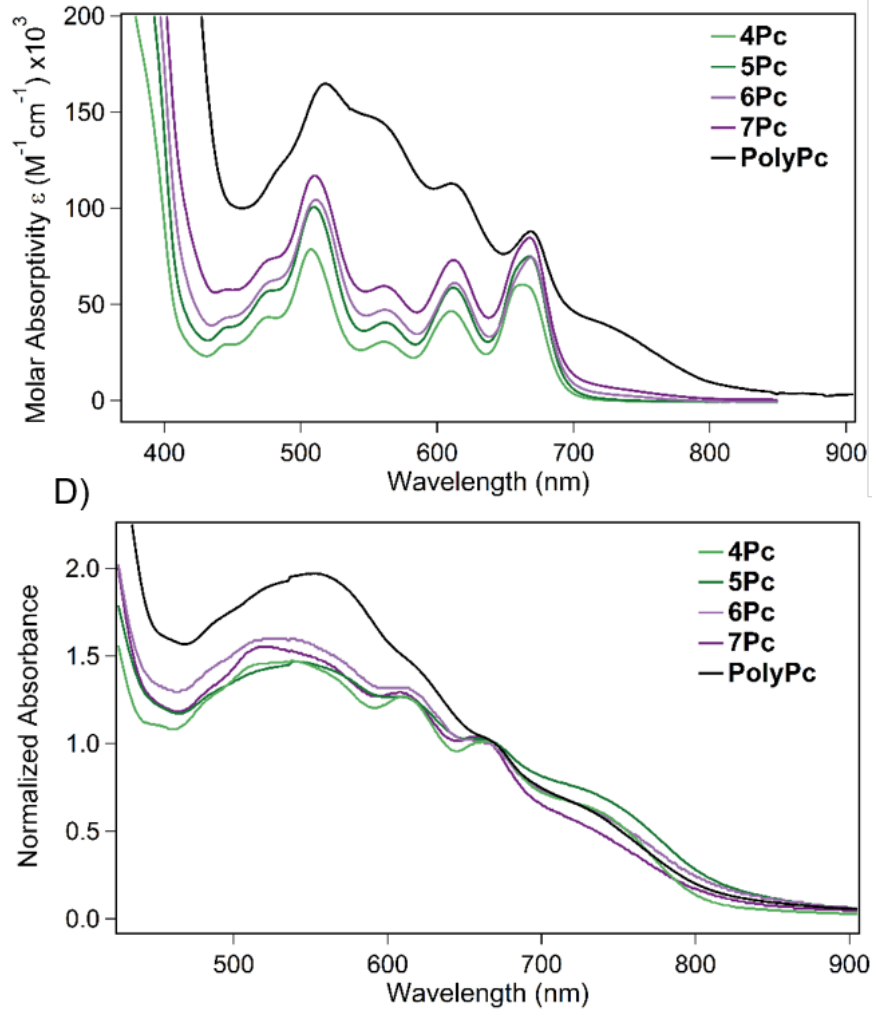

Figure 1. A) UV-vis spectra of oligomers 1Pc-3Pc measured in chloroform (12.5 $\mu \mathrm{M})$. B) UV-vis of oligomers ${ }_{4}$ Pc-7Pc (12.5 $\left.\mu \mathrm{M}\right)$ and PolyPc (arbitrary units for comparison) measured in chloroform. C) and D) UV-Vis of oligomers and PolyPc, drop cast from chloroform on a glass slide and plotted with the onset of absorption peak near $670 \mathrm{~nm}$ normalized to a value of 1 .

We therefore substituted the C-8 chain in NODIPS with a $\mathrm{C}-18$ chain to create the stronger solubilizing group, $n$ octadecyl-diisopropylsilylethynyl (NODDIPS). The polymerization was carried out between $\mathbf{1 A 2}$ ' and $\mathbf{1 B 2}$ at $60{ }^{\circ} \mathrm{C}$ to obtain a pentacene homopolymer (Scheme 4 ). The reaction time was limited to $8 \mathrm{~h}$ to access soluble polymers. The reaction mixture was precipitated into methanol and the solid was purified by Soxhlet extraction, consecutively with hexanes, chloroform and chlorobenzene. The molecular weight of the polypentacene from the chlorobenzene fraction was determined by gel permeation chromatography (GPC) using hot 1,2,4trichlorochlorobenzene $\left(150{ }^{\circ} \mathrm{C}\right)$ as the eluent against polyethylene standards. The polypentacene was found to have a number average molecular weight $\left(M_{n}\right)$ of $\sim 15.8$ $\mathrm{kg} \cdot \mathrm{mol}^{-1}$ with $Đ=\mathbf{2 . 1}$.

Steady State Absorption: The optical properties of oligomers ${ }_{1-7} \mathbf{P c}$, regiopure ${ }_{3} \mathbf{P c}$ and polypentacene were probed by steady state UV-visible absorption spectroscopy in solution and in thin-films (Figure 1). In solution, the oligomer spectra of $\mathbf{2} \mathbf{P c}$ through ${ }_{7} \mathbf{P c}$ are qualitatively similar, with minimal redshift as the number of pentacenes increases. Notably, in solution, there are only minute differences in the UV-vis spectra of syn-3Pc, anti-3Pc and mix-3Pc. In the longer wavelength region $(>550 \mathrm{~nm})$ the oligomers all resemble the absorption spectrum of the monomer. However, in the dimer and each of the higher oligomers a new set of absorption peaks appear between $425 \mathrm{~nm}$ and $550 \mathrm{~nm}$ (which we interpret as a vibrational progression associated with a fundamental absorption described below). These peaks have not been previously observed in other pentacene-containing materials. The height of this new absorption maximum, relative to the height of the peak at the onset of absorption, increases with oligomer length. The strong similarity of the longwavelength region in the oligomers to that of the monomer lead us to conclude that these long-wavelength features in all of these molecules are due to intra-pentacene vibrational progressions. We verified this conclusion with electronic structure calculations on $\mathbf{1 P c}, \mathbf{2} \mathbf{P c},{ }_{3} \mathbf{P c}$, and ${ }_{4} \mathrm{Pc}$.

Excited state (TD-DFT, see SI) calculations suggest that the absorption peak at $650 \mathrm{~nm}$ in the monomer is due to the fundamental HOMO-to-LUMO transition. However, corresponding calculations on the dimer reveal a more complex situation. The HOMO in the dimer comprises two parts: one that resembles what would be the HOMO localized on one isolated pentacene (homo $\mathrm{L}_{\mathrm{L}}$ in Figure 2), and another that resembles what would the HOMO on the other isolated pentacene $\left(\right.$ homo $\mathrm{R}_{\mathrm{R}}$ in Figure 2 ). In the full HOMO and HOMO-1 of the molecule, these orbitals are combined with different phases: the $\mathrm{HOMO}$ is $\left(\right.$ homo $_{\mathrm{L}}$ - homo ${ }_{R}$ ), and the HOMO-1 is $\left(\right.$ homo $\left._{\mathrm{L}}+\mathrm{homo}_{\mathrm{R}}\right)$. The situation for the lowest-energy unoccupied orbitals is similar: 
the molecular LUMO is approximated by ((lumo $\mathrm{L}_{\mathrm{L}}+\mathrm{lu}-$ $\left.\mathrm{mo}_{\mathrm{R}}\right)$, and the molecular LUMO+1 by $\left(\operatorname{lumo}_{\mathrm{L}}-\mathrm{lumo}_{\mathrm{R}}\right)$. We propose that the lower-energy transition in the dimer effectively promotes an electron from the HOMO to the LUMO, and the higher-energy transition effectively promotes an electron from the HOMO-1 to the LUMO+1.

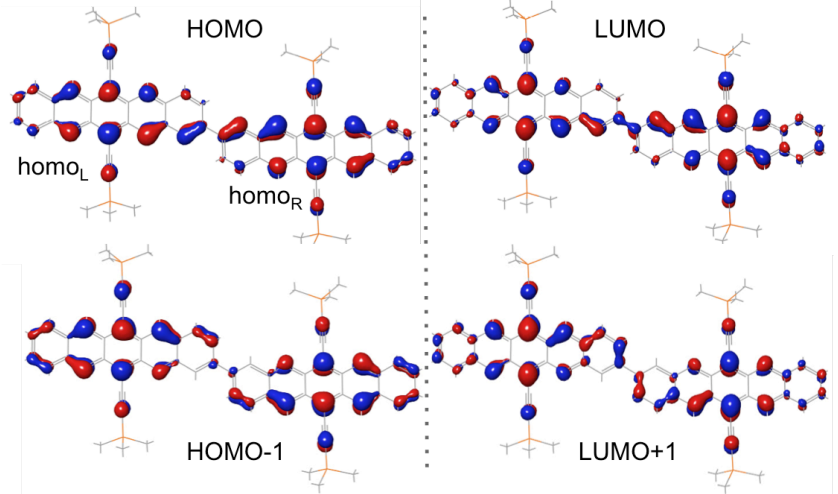

Figure 2. Highest occupied and lowest unoccupied molecular orbitals (HOMO and LUMO, respectively), along with the +1 and -1 orbitals.

The source of the energy separation between the two transitions lies in the nexus of the two pentacenes. In the HOMO there is a $\pi$-antibonding interaction between the two $\mathrm{C}$ atoms that form the pentacene-pentacene link; in the LUMO there is a $\pi$-bonding interaction in that space. By comparison in the HOMO-1 there is a $\pi$-bond between these two $\mathrm{C}$ atoms, and in the LUMO+1 there is a $\pi$ antibond. Thus the two "HOMO-to-LUMO" excitations are split by the formation versus destruction of the interpentacene $\pi$-interaction. In the lower-energy transition an unfavorable interaction is relieved in the ground state and a favorable interaction realized in the excited state; in the higher-energy transition the reverse is the case. We believe that similar effects occur in the higher oligomers. A complete discussion of these cases is complicated, particularly by the many geometrical degrees of freedom available to the higher oligomers. We will report more detailed results of these studies separately.

In the solution UV-vis, a modest red-shift of the onset of absorption is observed in the highest $(n>4)$ oligomers, indicating weak aggregation in chloroform. This aggregation is weakly concentration dependent, as expected, and strongly solvent dependent. For example, less aggregation was observed in solvents such as toluene, tetrachloroethylene and chloroform, while significant aggregation was observed in hexanes. ${ }^{10}$

Solid-state absorbance spectra were also obtained by drop casting oligomers on to a glass slide from chloroform. In the monomer $\mathbf{1 P c}$, the solution and solid-state spectra are nearly identical, indicating that the bulky NODIPS chains effectively prevent any significant crystallinity in the solid state and result in a highly amorphous solid. On the other hand, starting from the dimer containing NODIPS, a large degree of interaction is evidenced in the solid-state UVvis, presumably due to a "bricklayer" type packing that we have previously observed in the crystal structure of the dimer $^{12}$ and possible for all oligomers beyond the mono- mer, 1Pc. This interaction results in a loss of the clear vibronic peaks present in solution, as well as a significant red-shift of the absorption onset. Such significant solidstate interaction in these higher oligomers bodes well for their potential in electronic applications, where strong interactions resulting from planarity and $\pi-\pi$ stacking are typically desirable for organic materials. ${ }^{13}$ These strong interactions also help to explain the dramatic loss of solubility between monomeric TIPS-pentacene and the TIPSpentacene dimer, which necessitated the use of the more solubilizing NODIPS chain for higher oligomers. Notably, there are fairly significant differences in the solid-state spectra of syn-3Pc, anti-3Pc and mixture of trimers, despite their similarity in solution. These differences are therefore attributable to different capacities for effective solid-state packing, as confirmed by grazing-incidence wide-angle $x$-ray scattering (GIWAXS), vide infra. However, beyond the trimer, there are only subtle differences among oligomers $4-7 \mathbf{P c}$, suggesting that these longer oligomers are starting to converge in their characteristics towards that of a polymer.

Photostability: Acenes are notorious for their degradation in presence of light and oxygen. Longer oligoacenes are also particularly susceptible to intermolecular DielsAlders reactions upon thermal activation. To investigate the stability of oligopentacenes towards such undesirable processes, we carried out a qualitative photodegradation study involving irradiation of solutions of $\mathbf{1}_{-3} \mathbf{P c}$ in the presence of oxygen at similar molarities with respect to pentacene monomer. (see SI). The results indicate a significantly enhanced stability of oligomers relative to that of the monomer. The stark difference in stability enhancement may have its origin from the shortened excited state lifetime of the oligopentacenes and/or ultrafast deactivation of any photodegradation pathways specific to the singlet exciton. More comprehensive studies to understand the underpinnings of the stability of oligoand poly-pentacenes are currently underway in our group.

Cyclic Voltametry: In order to investigate how the energy levels vary as a function of oligomer length, we carried out cyclic voltammetry to determine the oxidation and reduction potentials. The good solubility of the oligopentacenes enabled their measurement in dichloromethane against a $\mathrm{Ag} / \mathrm{Ag}^{+}$reference (details in SI). The highest occupied molecular orbital (HOMO) and lowest unoccupied molecular orbital (LUMO) levels were obtained by calibrating the onset of oxidation (or reduction, for LUMO) to the $\mathrm{Fc} / \mathrm{Fc}^{+}$couple (Figure 3 ). ${ }^{14}$ The convergence of the band gap in this oligopentacene series is evident both from the frontier energy levels and from the UV-vis data. Similar to the oligopentacenes linked by the central ring reported by Lehnherr et al., polymer-like behavior is approached starting at ${ }_{\mathbf{4}} \mathbf{P c}{ }^{6 \mathrm{~d}}$ The band gap decrease is a result of the HOMO being raised as successive pentacene units are added, while the LUMO remains fairly constant. The raising of the HOMO level with increasing oligomer length has also been reported for phenylene ${ }^{15}$ and thiophene systems..$^{\text {a }}$ Repeated scans revealed that the compounds all display good redox stability within the poten- 
tial window measured, with the exception of the heptamer which had an irreversible reduction wave.

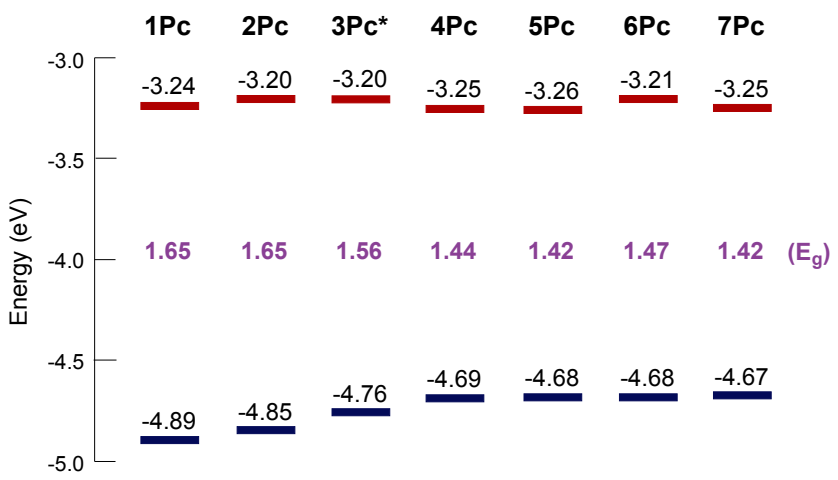

Figure 3. Electrochemical properties of oligopentacenes obtained from cyclic voltammetric studies. $3 \mathbf{P c}^{*}$ indicates the sample used was mix-3Pc.

Thermal Properties: Thermal gravimetric analysis (TGA) revealed excellent thermal stability of these pentacene oligomers, with all compounds exhibiting a decomposition temperature $\left(\mathrm{T}_{\mathrm{d}}\right)$ of at least $370{ }^{\circ} \mathrm{C}$ under nitrogen flow. A summary of these values can be seen in Table 1 . As the oligomer length increases there is no appreciable change in the $T_{d}$ of the compounds, which is likely attributable to the almost identical empirical chemical formula of the oligomers. For example, the smallest oligomer (2Pc) has a $\mathrm{T}_{\mathrm{d}}$ of $371{ }^{\circ} \mathrm{C}$, while the largest oligomer, $\left.{ }_{7} \mathbf{P c}\right)$ has a $\mathrm{T}_{\mathrm{d}}$ of $382{ }^{\circ} \mathrm{C}$.

The thermal transitions of these materials were studied by differential scanning calorimetry (DSC). Only $\mathbf{2} \mathbf{P c}$ exhibited phase transitions, with a glass transition temperature of $134{ }^{\circ} \mathrm{C}$ and a melting point of $166{ }^{\circ} \mathrm{C} .{ }^{10}$ However these transitions are only observed in the first heating cycle, due to the decomposition that is observed after the compound reaches its melting point under oxygen at high temperature. These non-reversible phase transitions agree with DSC performed on similar materials. ${ }^{8}$ For the larger oligomers, no phase transitions were observed within the range of temperatures explored.

Table 1: Thermal properties of oligopentacene obtained by Thermogravimetric analysis (TGA)

\begin{tabular}{|c|c|c|}
\hline Entry & Compound & $\begin{array}{c}\text { Decomposition } \\
\text { temperature, } T_{d}\left[{ }^{\circ} \mathrm{C}\right]\end{array}$ \\
\hline $\mathbf{1}$ & $\mathbf{2 P c}$ & 371 \\
\hline $\mathbf{2}$ & Mixture-3Pc & 373 \\
\hline 3 & anti-3Pc & 374 \\
\hline 4 & syn-3Pc & 372 \\
\hline 5 & $\mathbf{4 P c}$ & 374 \\
\hline 6 & $\mathbf{5 P c}$ & 380 \\
\hline 7 & $\mathbf{6 P c}$ & 380 \\
\hline 8 & 7Pc & 382 \\
\hline
\end{tabular}

The measurement was carried out under constant flow of nitrogen with heating rate of $10^{\circ} \mathrm{C} / \mathrm{min}$. Refer to supporting information for additional details.
Thin-Film Morphology: In order to gain insights into the packing interactions of these materials, grazing incidence wide angle X-ray scattering (GIWAXS) data was collected for all oligopentacene films at incidence angles in the range of $0.2-0.22^{\circ}$, which is above the critical angle of the oligopentacenes (ca. $0.17^{\circ}$ ) and below the critical angle of the substrate (ca. $0.24^{\circ}$ ). The crystal structure of these NODIPS-functionalized oligopentacenes has not been previously reported, and the crystalline content of these samples is too low for a detailed analysis (i.e., too few diffraction peaks). However, we have previously reported the crystal structure of $\mathbf{2} \mathbf{P c}$ where the TIPS solubilizing groups are used. ${ }^{12}$ This compound, and several other classes of functionalized acenes ${ }^{3,16}$ exhibit a triclinic unit cell (space group $\mathrm{P} \overline{1}$ ) in bulk and thin films. We used these studies to guide interpretation of our data.

First, we investigate the morphology of the regiopure trimers and compare it to the mixed product to understand how any differences may arise from these two classes of materials. Figure $4 \mathrm{~A}$ displays GIWAXS data for the annealed anti-3Pc thin film, and Figure $4 \mathrm{~B}$ shows the out-ofplane line cuts $\left(q_{y}=0\right)$ of the same oligomer before and after annealing at $200{ }^{\circ} \mathrm{C}$ for $30 \mathrm{~min}$. The $2 \mathrm{D}$ scattering pattern is largely diffuse, meaning the film has a high amorphous content, but there are signatures of oriented crystallites along the out-of-plane $z$-axis (spots/arcs along $q_{z}$ rather than isotropic rings). Diffraction peaks in the ascast film are weak and broad along the $q_{\mathrm{z}}$ axis, but annealing increases their intensity and narrows the line shape, which demonstrates that crystallinity is enhanced with heat treatment. Moreover, the first-order peak is detected at $q_{\mathrm{z}}{ }^{*}=0.52 \AA^{-1}$, corresponding with a periodicity of $d=$ $2 \pi / q_{z}{ }^{*}=12.1 \AA$, and higher-order peaks are detected at $2 q_{z}{ }^{*}=1.05 \AA^{-1}$ and $3 q_{z}{ }^{*}=1.58 \AA^{-1}$. Using the lattice parameters for $\mathbf{1} \mathbf{P c}{ }^{8}$, we attribute these peaks to scattering from $\{002\}$ and $\left\{\mathrm{OO}_{3}\right\}$ planes. A comparison between the predicted and observed values is included in Table 2 . An additional peak is observed at $q_{z}=1.33 \AA^{-1}$, corresponding to an interlayer periodicity of $0.47 \AA$, which is consistent with scattering from $\{111\}$ planes. Scattering from \{0o1\} planes is indicative of an edge-on crystallite orientation, where the direction of $\pi-\pi$ stacking is in the plane of the film.

Table 2: Predicted positions of diffraction peaks for 6,13-bis(diisopropyloctylsilylethynyl)pentacene ${ }^{8}$ and measured positions for anti-3Pc.

\begin{tabular}{|l|l|l|l|}
\hline Plane & $\begin{array}{l}\text { Predicted } \\
q_{z}\left(\AA^{-1}\right)\end{array}$ & $\begin{array}{l}\text { Measured } q_{z} \\
\left(\AA^{-1}\right)\end{array}$ & $\begin{array}{l}\text { Measured } \\
d(\AA)\end{array}$ \\
\hline$($ oo1 $)$ & 0.51 & 0.52 & 12.1 \\
\hline$(002)$ & 1.03 & 1.05 & 0.60 \\
\hline$(111)$ & 1.24 & 1.33 & 0.47 \\
\hline$(003)$ & 1.54 & 1.58 & 0.40 \\
\hline
\end{tabular}



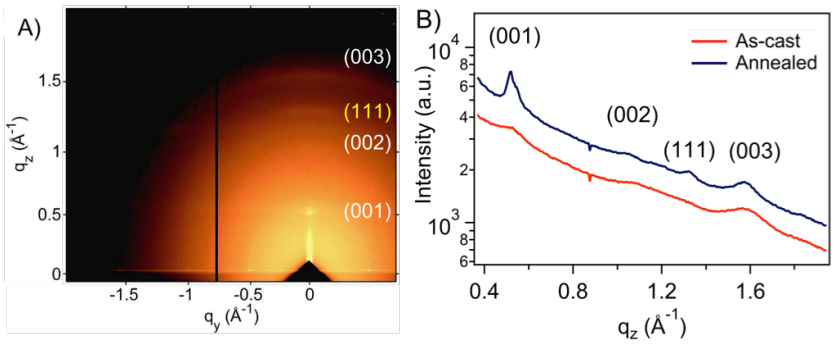

Figure 4. A) 2D GIWAXS patterns of the annealed anti-3Pc film (incident tangle $\alpha_{\mathrm{i}}=\mathbf{0 . 2 2 ^ { \circ }}$ ). B) Scattering profiles of ascast and annealed anti-pentacene trimer (anti-3Pc) along the $q_{z}$-axis at $q_{y}=$ o (out-of-plane profile).

Scattering from $\{111\}$ planes is associated with a face-on orientation that is less favorable for transistors. anti-3Pc Adopts both of these orientations, which is consistent with other thin film studies of functionalized acenes. ${ }^{8,6 a}$ Figure 5 summarizes the out-of-plane intensity profiles for all the oligopentacenes considered in this report. The highest crystallinity is observed in the annealed trimer series, where it is higher in the order anti-3Pc $>$ mix-3Pc $>$ syn-3Pc. All other higher oligomers $\left({ }_{4} \mathbf{P c}-\mathbf{P} \mathbf{P c}\right)$ materials exhibit very low crystallinity, and annealing has little or no impact on ordering. This observation is reasonable as more regioisomers are created for higher oligomers, which can alter packing interactions. Understanding these fundamental details of poly- and oligo-pentacenes will be important in to design the appropriate architectures for device fabrication.

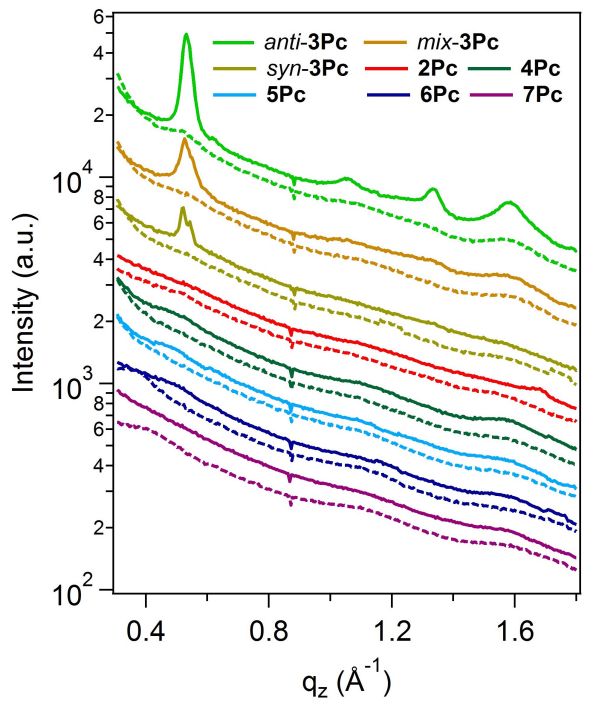

Figure 5. Out-of-plane line cuts $\mathrm{I}\left(q_{z}\right)$ for as-cast (dashed lines) and thermally annealed (at $200^{\circ} \mathrm{C}$, solid lines) oligopentacene films. Incidence angle is $\alpha_{\mathrm{i}}=0.20^{\circ}$.

\section{CONCLUSION}

We report a facile and scalable method for the synthesis of solution processable higher oligomers of pentacenes (2Pc-7Pc), in addition to the first pentacene homopolymer. Exploiting the arene functional handle allows for a constant ratio of solubilizing/stabilizing units to pentacene as oligomer length increases, which results in excellent solubility in common organic solvents. Importantly, regiopure pentacene trimers $(s y n-3 \mathbf{P c}$ and anti-3Pc) were also synthesized and compared to the regiomixture trimer $(m i x-3 \mathbf{P c})$, revealing several interesting characteristics: while there were no significant changes in the solution UV-vis spectroscopy, the solid-state UV-vis signature was strongly affected by regioisomerism. We showed that changes are attributable to the different packing interactions of the different regioisomers, as characterized by GIWAXS. The crystallinity of anti-3Pc was significantly greater than mix-Pc and syn-Pc. GIWAXS also revealed minimal ordering in the higher oligomers, likely due to the presence of a large number of regioisomers. In all cases, crystalline order was increased upon thermal annealing. The solution UV-vis spectroscopy revealed the occurrence of high-energy peak in the region between $425 \mathrm{~nm}$ and $550 \mathrm{~nm}$ that intensifies as the length of the oligomer increases. This absorption, which effectively increases the absorption profile in the visible region, is attributed to an inter-pentacene $\pi$ to $\pi^{*}$ transition. Cyclic voltammetry revealed an increase in the HOMO level for each homologous addition of pentacene, with polymer-like behavior approached at an oligomer length of four. The DSC and TGA experiments reveal that the oligopentacenes are thermally stable and have consistent decomposition temperature irrespective of oligomer length $\left(371-382{ }^{\circ} \mathrm{C}\right)$. Except for $\mathbf{2} \mathbf{P c}$, all the oligomers displayed no phase transition during the heating cycle while 2 Pc had nonreversible phase transition. The application of these oligo/polypentacenes in various semiconductor applications and determination of charge transport properties are currently under progress.

\section{ASSOCIATED CONTENT}

Supporting Information. Synthesis, characterization and other spectroscopic data. This material is available free of charge via the Internet at http://pubs.acs.org.

\section{AUTHOR INFORMATION}

\section{Corresponding Author}

E-mail: lcampos@columbia.edu

\section{Author Contributions}

* These authors contributed equally.

\section{Notes}

The authors declare no competing financial interests.

\section{ACKNOWLEDGMENT}

This work was funded by the Office of Naval Research Young Investigator Award (No. Nooo14-15-1-2532), ACS Petroleum Research Fund, 3M Non-Tenured Faculty Award, and Cottrell Scholar Award. S.N.S. and A.B.P. thank the NSF for GRFP (DGE 11-44155). J.Z.L. thanks the A*STAR Graduate Academy from Singapore for a graduate fellowship. Research was carried out in part at the Center for Functional Nanomaterials, Brookhaven National Laboratory, which is supported by the US Department of Energy, Office of Basic Energy Sciences, under Contract No. DE-ACo2-98CH1o886. 
We are grateful to Colin Nuckolls for use of his UV-vis spectrophotometer and James Eagan and Geoffrey Coates for running GPC samples.

\section{REFERENCES}

(1) (a)Katz, H. E.; Bao, Z.; Gilat, S. L. Acc. Chem. Res. 2001, 34, 359-369; $\quad$ (b)Ito, K.; Suzuki, T.; Sakamoto, Y.; Kubota, D.; Inoue, Y.; Sato, F.; Tokito, S. Angew. Chem. 2003, 115, 1191-1194; $\quad$ (c)Anthony, J. E. Angew. Chem. Int. Ed. 2008, 47, 452-483; (d)Zade, S. S.; Bendikov, M. Angew. Chem. Int. Ed. 2010, 49, 4012-4015; $\quad$ (e)Ball, M.; Zhong, Y.; Wu, Y.; Schenck, C.; Ng, F.; Steigerwald, M.; Xiao, S.; Nuckolls, C. Acc. Chem. Res. 2015, 48, 267-276;

(f)Low, J. Z.; Sanders, S. N.; Campos, L. M. Chem. Mater. 2015, 27, 5453-5463; (g)Tsefrikas, V. M.; Scott, L. T. Chem. Rev. 20o6, 106, 4868-4884; $\quad$ (h)Sundar, V. C.; Zaumseil, J.; Podzorov, V.; Menard, E.; Willett, R. L.; Someya, T.; Gershenson, M. E.; Rogers, J. A. Science 2004, 303, 1644-1646; (i)Bunz, U. H. F. Acc. Chem. Res. 2015, 48, 1676-1686; （j)Sanders, S. N.; Kumarasamy, E.; Pun, A. B.; Steigerwald, M. L.; Sfeir, M. Y.; Campos, L. M. Angew. Chem. Int. Ed. 2016, DOI: 10.1002/anie.201510632..

(2) (a)Yen-Yi, L.; Gundlach, D. I.; Nelson, S. F.; Jackson, T. N. Electron Devices, IEEE Transactions on 1997, 44, 1325-1331; (b)Park, S. K.; Jackson, T. N.; Anthony, J. E.; Mourey, D. A. Appl. Phys. Lett. 2007, 91, 063514 ; $\quad$ (c)Afzali, $\quad$ A.; Dimitrakopoulos, C. D.; Breen, T. L. J. Am. Chem. Soc. 2002, 124, 8812-8813; $\quad$ (d)Jo, S. B.; Kim, H. H.; Lee, H.; Kang, B.; Lee, S.; Sim, M.; Kim, M.; Lee, W. H.; Cho, K. ACS Nano 2015, 9, 8206-8219;

(e)Herwig, P. T.; Müllen, K. Adv. Mater. 1999, 11, 480-483.

(3) Anthony, J. E.; Brooks, J. S.; Eaton, D. L.; Parkin, S. R. J. Am. Chem. Soc. 2001, 123, 9482-9483.

(4) (a)Anthony, J. E. Chem. Rev. 2oo6, 106, 5028-5048; (b)Bendikov, M.; Wudl, F.; Perepichka, D. F. Chem. Rev. 2004, 104, 4891-4946.

(5) (a)Fudickar, W.; Linker, T. J. Am. Chem. Soc. 2012, 134, 15071-15082; (b)Maliakal, A.; Raghavachari, K.; Katz, H.; Chandross, E.; Siegrist, T. Chem. Mater. 2004, 16, 49804986.

(6) (a)Lehnherr, D.; Gao, J.; Hegmann, F. A.; Tykwinski, R. R. J. Org. Chem. 2oo9, 74, 5017-5024; (b)Okamoto, T.; Bao, Z. J. Am. Chem. Soc. 2007, 129, 10308-10309; $\quad$ (c)Lehnherr, D.; McDonald, R.; Ferguson, M. J.; Tykwinski, R. R. Tetrahedron 2008, 64, 11449-11461; (d)Lehnherr, D.; Murray, A. H.; McDonald, R.; Tykwinski, R. R. Angew. Chem. Int. Ed. 2010, 49, 6190-6194; (e)Tokito, S.; Weifurtner, K.-H.; Fujikawa, H.; Tsutsui, T.; Taga, Y. Proc. SPIE-Int. Soc. Opt. Eng. 2001, 4105, 69-74; (f)Porz, M.; Paulus, F.; Höfle, S.; Lutz, T.; Lemmer, U.; Colsmann, A.; Bunz, U. H. F. Macromol. Rapid Commun. 2013, 34, 1611-1617.

(7) (a)Capozzi, B.; Dell, E. J.; Berkelbach, T. C.; Reichman, D. R.; Venkataraman, L.; Campos, L. M. J. Am. Chem. Soc. 2014, 136, 10486-10492; $\quad$ (b)Koch, F. P. V.; Smith, P.; Heeney, M. J. Am. Chem. Soc. 2o13, 135, 13695-13698; (c)Koch, F. P. V.; Heeney, M.; Smith, P. J. Am. Chem. Soc. 2013, 135, 13699-13709; $\quad$ (d)Zhang, L.; Colella, N.
S.; Liu, F.; Trahan, S.; Baral, J. K.; Winter, H. H.; Mannsfeld, S. C. B.; Briseno, A. L. J. Am. Chem. Soc. 2013, 135, 844-854;

(e)Liu, F.; Espejo, G. L.; Qiu, S.; Oliva, M. M.; Pina, J.; Seixas de Melo, J. S.; Casado, J.; Zhu, X. J. Am. Chem. Soc. 2015, 137, 10357-10366; (f)Müllen, K.; Wegner, G.; Electronic Materials: The Oligomer Approach; Wiley-VCH: New York: 1998.

(8) Chen, J.; Subramanian, S.; Parkin, S. R.; Siegler, M.; Gallup, K.; Haughn, C.; Martin, D. C.; Anthony, J. E. J. Mater. Chem. 2008, 18, 1961-1969.

(9) (a)Plunkett, K. N.; Godula, K.; Nuckolls, C.; Tremblay, N.; Whalley, A. C.; Xiao, S. Org. Lett. 2009, 11, 2225-2228; (b)Swartz, C. R.; Parkin, S. R.; Bullock, J. E.; Anthony, J. E.; Mayer, A. C.; Malliaras, G. G. Org. Lett. 2005, 7, 31633166; $\quad$ (c)Lehnherr, D.; Gao, J.; Hegmann, F. A.; Tykwinski, R. R. Org. Lett. 2oo8, 10, 4779-4782; (d)Anthony, J. E.; Eaton, D. L.; Parkin, S. R. Org. Lett. 2002, 4, 15-18; (e)Lehnherr, D.; McDonald, R.; Tykwinski, R. R. Org. Lett. 2008, 10, 4163-4166; (f)Lehnherr, $\quad$ D.; Tykwinski, R. R. Org. Lett. 2007, 9, 4583-4586;

(g)Miao, Q.; Chi, X.; Xiao, S.; Zeis, R.; Lefenfeld, M.; Siegrist, T.; Steigerwald, M. L.; Nuckolls, C. J. Am. Chem. Soc. 2006, 128, 1340-1345; (h)Payne, M. M.; Odom, S. A.; Parkin, S. R.; Anthony, J. E. Org. Lett. 2004, 6, 33253328; (i)Takahashi, T.; Kitamura, M.; Shen, B.; Nakajima, K. J. Am. Chem. Soc. 200o, 122, 12876-12877; (j)Lu, J.; Ho, D. M.; Vogelaar, N. J.; Kraml, C. M.; Bernhard, S.; Byrne, N.; Kim, L. R.; Pascal, R. A. J. Am. Chem. Soc. 2006, 128, 17043-17050; $\quad$ (k)Zhao, Y.; Mondal, R.; Neckers, D. C. J. Org. Chem. 2oo8, 73, 55065513; (l)Bénard, C. P.; Geng, Z.; Heuft, M. A.; VanCrey, K.; Fallis, A. G. J. Org. Chem. 20o7, 72, 7229-7236.

(10) Refer to supporting information.

(11) Okamoto, T.; Reese, C.; Senatore, M. L.; Tang, M. L.; Jiang, Y.; Parkin, S. R.; Bao, Z. Synth. Met. 2010, 16o, 2447-2451.

(12)Sanders, S. N.; Kumarasamy, E.; Pun, A. B.; Trinh, M. T.; Choi, B.; Xia, J.; Taffet, E. J.; Low, J. Z.; Miller, J. R.; Roy, X.; Zhu, X. Y.; Steigerwald, M. L.; Sfeir, M. Y.; Campos, L. M. J. Am. Chem. Soc. 2015, 137, 8965-8972.

(13) (a)Wu, W.; Liu, Y.; Zhu, D. Chem. Soc. Rev. 2010, 39, 14891502; $\quad$ (b)Coropceanu, V.; Cornil, J.; da Silva Filho, D. A.; Olivier, Y.; Silbey, R.; Brédas, J.-L. Chem. Rev. 2007, 107, 926-952.

(14)You, J.; Dou, L.; Yoshimura, K.; Kato, T.; Ohya, K.; Moriarty, T.; Emery, K.; Chen, C.-C.; Gao, J.; Li, G.; Yang, Y. Nat Commun 2013, 4, 1446.

(15) Banerjee, M.; Shukla, R.; Rathore, R. J. Am. Chem. Soc. 20o9, 131, 1780-1786.

(16) (a)Kline, R. J.; Hudson, S. D.; Zhang, X.; Gundlach, D. J.; Moad, A. J.; Jurchescu, O. D.; Jackson, T. N.; Subramanian, S.; Anthony, J. E.; Toney, M. F.; Richter, L. J. Chem. Mater. 2011, 23, 1194-1203; (b)Mannsfeld, S. C. B.; Tang, M. L.; Bao, Z. Adv. Mater. 2011, 23, 127-131; (c)Kang, J.; Shin, N.; Jang, D. Y.; Prabhu, V. M.; Yoon, D. Y. J. Am. Chem. Soc. 20o8, 130, 12273-12275. 
Insert Table of Contents artwork here

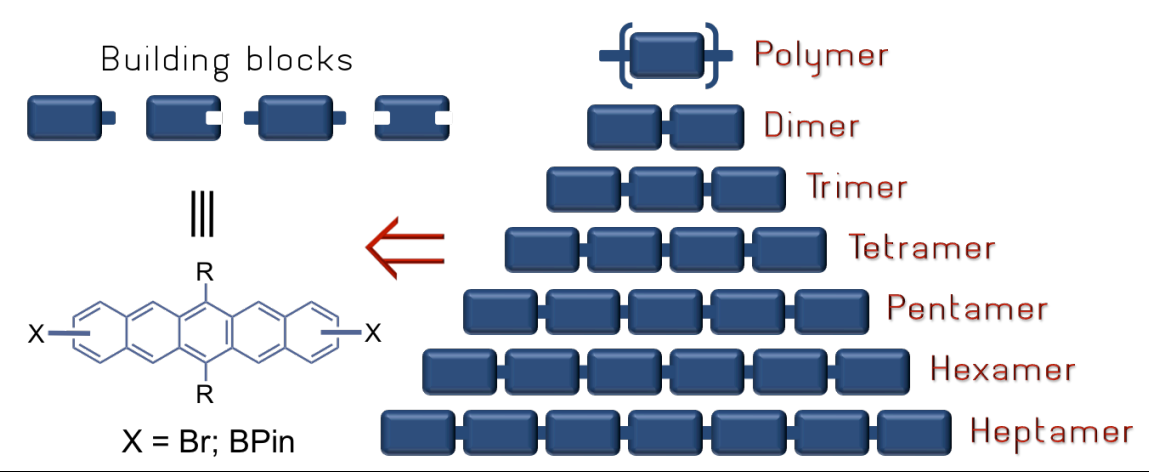

